\title{
A NEW EU CHALLENGE: INCREASE SUPPLY CHAIN MANAGEMENT PERFORMANCE BY INTERNET OF THINGS. A STUDY ON ROMANIAN ECONOMY
}

\author{
Mircea GEORGESCU \\ Alexandru Ioan Cuza University of Iasi, Romania \\ mirceag@uaic.ro \\ Roxana IBANESCU \\ Alexandru Ioan Cuza University of Iasi, Romania \\ ibanescu_roxana@yahoo.com
}

\begin{abstract}
The adoption of Internet of Things technology in Supply Chain Management improves the overall performance and relationship between the supply chain members well as the relationship with the customers, competitors, and suppliers. Since the decision of adopting Internet of Things technology is influenced by the factors underlying each member organization of the supply chain, we can consider that the supply chain performance can be measured from three points of view: organizational factors, inter-organizational factors and technological factors. The main purpose of our present research is to analyze the performance factors that are influencing the adoption of Internet of Things technology in Supply Chain Management. In order to identify and examine the influent factors, a quantitative research it was conducted. We decided about it in aid of understanding the determinants, which characterize an organization and the relations between it and its members, factors that are contributing to better prosperity of the organization. For testing the hypotheses of the present research, a logistic regression model it was used, which designed the relationship between an independent variables and a dichotomous dependent variable. The participants on the selected sample are employees from companies active in the field of agriculture, from Romanian country. The results of the present research point out that, in general, the organizational factors alongside the technological ones have a partial contribution and a significant effect on the adoption of Internet of Things technology, while the inter-organizational factors have no implications. The organizational factors, characterized by the size and financial resources, together with the technological ones (in particular, the advantage offered by a new product and the rate of return on investment) are important predictors of the adoption of Internet of Things technology.
\end{abstract}

Keywords: Internet of Things, Performance factors, Supply Chain Management.

JEL classification: L25, M11, L86

DOI: $10.24818 / \mathrm{ie} 2020.01 .01$

\section{Introduction}

In present, the Internet of Things represents a new stage in the evolution of the Internet that brings major changes in our world, transforming it in a smart virtual world capable of sensing, analysing and adapting to new conditions to contribute to improving the quality of life and safety of people. In this context, Internet of Things can be seen as a global infrastructure of interconnected physical objects that offers transparency to the supply chain management. Despite the advantages offered by it, however, it has not been widely adopted in the supply 
chain and logistics industry, some relevant studies been related to supply chain innovations, agriculture supply chain, supply chain risk management, social responsibility, warehousing [8]. The use of Internet of Things in the manufacturing and supply chains is known as Industrial Internet of Things (IIoT) [6] and is being applied to collect on-site real-time information, with direct effects on operations of enterprises. Some authors affirms that the adoptions of IoT technology must consider several factors, as standards, cost, patents, the infrastructure of the overall supply chain, return on investment (ROI rate), compatibility, and technology transfer. The adoption of Internet of Things in the management of supply chain represents a complicated process, where organizations may have different expectations and attitudes toward accepting the new technologies [17].

\section{Literature review}

The Internet of Things represents a determinant factor in changing supply chains, starting from a linear process, carried out step by step, to a continuous flow of data based on information. Among the benefits of using IoT in supply chain management, we can mention improving communication and customer experience as well as increasing the number of innovations. Internally, companies use this technology for real-time activities such as collecting, analysing and generating data to obtain information about customers, processes, services, markets and partner companies that can be used later for making decisions. Externally, by using the Internet, IoT contributes to the design of scalable, fast, dedicated and active platforms. The global economic evolution leads to an increase of the competitiveness between organizations, which can be sustained by the creation of a network of organizations, known as a supply chain that collaborates and coordinates its activities to deliver a product on the market. The organizations involved in the efficient production and supply of products to customers are managed in the form of economic systems that implement internal mechanisms and develop chain incentives to ensure timely execution of production and delivery commitments.

The systems integration is a network of business relationships, realized to manage the upstream and downstream flows of products, services, finances and information from a source to a client being known as the supply chain management [12]. In the context of increasing the number of companies affiliated with the supply chains in today's business environment and the benefits obtained from these associations, we can see that supply chain management has become an important component of the organizations management systems, contributing both to reducing costs and to maintain and improve the quality of goods and services delivered.

\section{Research hypothesis}

To improve the performance in the supply chain management by using the Internet of Things, the evolution of technology is monitored along with the relationships between members of the supply chain as well as the relationships with the customers, competitors, and suppliers. Since the decision to adopt Internet of Things technology is influenced by the factors underlying each member organization of the supply chain, we can consider that the supply chain performance can be measured from three points of view: organizational factors, inter-organizational factors and technological factors [13]. To analyse the factors that are influencing the adoption of Internet of Things technology in supply chain management, we use a series of hypothesis based on the performance factors.

\subsection{Organizational factors}

At the organizational level, the research aims at the organizational structure of the company establishing as evaluation factors: the size (measured by revenues, number of employees), the financial resources and the degree of centralization of the company. 
The size of a company and the financial resources are factors that influence the organizational structure as the company is larger and has more financial resources, the more technologically advanced the company is considered. From financial resources point of view, these contribute to improving the ability of large companies to accept the risks arising from investing in new technologies. Previous literature shows that only a small number of studies have focused on the adoption of IoT in small and medium-sized enterprises, despite the exponential growth of the interest shown on IoT technology in these enterprises, targeting more large enterprises that they have benefited more from this technology, benefiting from improved sales and lower costs [10] [1]. Thus it is hypothesized that:

H1. There is a positive relationship between the size of the company and the adoption of Internet of Things technology in SCM.

$\mathrm{H} 2$. There is a positive relationship between the financial resources of the company and the adoption of Internet of Things technology in SCM.

The need for power allocation appears along with the increase of the company size, the action carried out by its management to the lower levels, thus the power is distributed differentially between the social positions within a company. This action is known as centralization aimed at the participation of members from various departments in decision making (regarding resource allocation and organizational policy) and the hierarchy of authority that denotes the degree of concentration in the decision-making process regarding task performance [5] [11]. From the centralization point of view, link with the adoption of devices and technologies specific to the Internet of Things, some authors [9] assert that there is a positive connection, thus supporting top management would significantly influence the adoption of Internet technology. Other authors [15], argue that decentralized organizations are more likely to adopt innovative and integrative technologies, allowing better coordination between the members of the supply chain, as well as between the people in the company. Thus it is hypothesized that: $\mathrm{H} 3$. There is a negative relationship between the degree of centralization of the company and the adoption of Internet of Things technology in SCM.

\subsection{Inter-organizational factors}

The efficient management of the supply chain requires trust between partners, this being defined by the expectation expressed by an agent, that his business partner will behave in a mutually acceptable manner not exploiting the vulnerabilities of the other [7]. Organizations that have high values regarding the degree of trust in their partners, developed through cooperation and information exchange, tend to have a high degree regarding the adoption of devices and technologies specific to the Internet of Things, this being done to strengthen the relations and improve the communication between the partners. Thus it is hypothesized that: $\mathrm{H} 4$. There is a positive relationship between inter-organizational trust between the members of a supply chain and the adoption of Internet of Things technology in SCM.

The market information transmitted among the partners in a supply chain and the activities undertaken by the independent companies (two or more) are co-opted to orient the current and future needs of the customers, in other words, they are pursued with the purpose of creating an individual relationship sensitive to market demands, known as inter-organizational market orientation [14]. The adoption of technologies specific to the Internet of Things in companies characterized by a market orientation helps to increase the speed and accuracy of deliveries, improving the performance for end customers and their responsiveness, while improving the supply chain of which the companies are part, the information being efficiently distributed among the supply chain partners. Thus it is hypothesized that:

H5. There is a positive relationship between the inter-organizational market orientation and the adoption of Internet of Things technology in SCM. 
www.conferenceie.ase.ro

\subsection{Technological factors}

In addition to the organizational and inter-organizational approach, we are also considering an approach of the technological factors that reveal aspects of the technology itself. Technological factors influence how equipment is used in a company and how it operates. Due to increased dependence on equipment, technological factors are currently having a significantly greater effect on the performance of a business compared to previous years [1] [3]. Technological developments characterized by innovation contribute to the adoption of devices and technology specific to the Internet of Things, being an important aspect taken into consideration. The authors [2] examined the characteristics of innovations individually and in common with other organizations and noted that the characteristics of innovation such as perceived usefulness, intention to use, ease of use, compatibility, relative advantage, and complexity positively contribute to the adoption of new technologies in an organization as well as in member organizations of a supply chain. As individual factors are not taken into account in this research, only aspects of perceived usefulness and ease of use will be studied further. The two characteristics represents dimensions of the advantage offered by a new product, being a precedent for adopting the technology specific to the Internet of Things. Thus it is hypothesized that:

H6. There is a positive relationship between new product advantage and the adoption of Internet of Things technology in SCM.

Since the relative advantage is often measured in financial terms, the Return on investment rate (known as the ROI rate) and the period of time until the ROI is reached are used as indicators of measuring the advantage over the previous technology. Thus it is hypothesized that:

$\mathrm{H} 7$. There is a positive relationship between the ROI rate targeted by the company and the adoption of Internet of Things technology in SCM.

H8. There is a negative relationship between the period of time until the ROI rate reached by the company and the adoption of Internet of Things technology in SCM.

The rate of recovery of the investment offers the possibility to evaluate the efficiency of the investment made by the companies. This can be found in the form of a percentage or ratio due to the distribution of the benefit (return) of the investment at its cost.

\section{Research results}

The survey subjects of this research questionnaire are employees from companies active in the field of agriculture, from the area of Moldova, from Romania, randomly chosen who have management or decision-making functions, at least 2 years old and who has/have been related to the Internet of Things technology. The questionnaire was sent by e-mail for completion to 292 professionals, being recovered from 188 questionnaires (64.38\% recovery rate), out of which 112 questionnaires were valid (59.57\%). The questionnaire of this research includes five parts, structured as follows:

Part I. Includes data on the respondent and the company in which it operates, being made up of different types of questions: grid (with only one answer), open and closed dichotomies, totaling 15 questions.

Part II - V. Each part contains an answer matrix-type opinion question using a Likert scale and a scale aimed at the implementation intention, offering the possibility to measure several aspects, among which: The importance of improving certain aspects in company, level of adoption, the relationship between SCM members and characteristics of IoT adoptions in SCM. For testing the research hypotheses a logistic regression model was used that models the relationship between an independent variables and a dichotomous dependent variable, which takes values 1 and 0 . This analysis is consistent with previous studies conducted to examine 
the factors that may influence technology innovation and adoption in an organization, individually or collectively when we are talking about member companies in a supply chain. The adoption of devices and technologies specific to the Internet of Things was reduced for the explanatory variables: size, financial resources, centralization, inter-organizational trust, interorganizational market orientation, new product advantage, ROI rate, and the period of time until the ROI rate is reached.

Therefore, the theoretical model can be defined as follows:

$$
\gamma=\beta_{0}+\beta_{1} X_{1}+\beta_{2} X_{2}+\beta_{3} X_{3}+\beta_{4} X_{4}+\beta_{5} X_{5}+\beta_{6} X_{6}+\beta_{7} X_{7}+\beta_{8} X_{8}(1)
$$

Where,

$\gamma=$ represents the adoption of IoT technology

$\mathrm{X} \_1$ = used to measure the company size

$\mathrm{X} \_2=$ used to measure the financial resources

$X \_3=$ used to measure the centralization

X_4 = used to measure the inter-organizational trust

$X \_5=$ used to measure the inter-organizational market orientation

$\mathrm{X} \_6=$ used to measure the new product advantage

$\mathrm{X} \_7$ = used to measure the ROI rate

$\mathrm{X} \_8=$ used to measure the period of time until the ROI rate is reached

$\beta \_0=$ is a constant representing the natural logarithm of the odds status for the null values of all variables

Because the independent variables: company size, financial resources, ROI rate, the period of time until the ROI rate is reached has several non-numeric variants, their transformations were performed in binary variables to record the transformations undergone to meet a specific condition, using 1 for present and 0 for absent. For the other variables, we can consider the following conditions.

We will target in our study small-medium size companies, defining the odds ratio for the variable Company size based on the number of employees, and for the variable Financial resources based on the net profit.

$$
\begin{aligned}
& \text { Company size }=\left\{\begin{array}{c}
1, \text { if no employees }<250 \\
0, \text { if no employees } \geq 250
\end{array}\right. \\
& \text { Financial resources }=\left\{\begin{array}{c}
1, \text { Net profit }<100.000 \\
0, \text { Net profit } \geq 100.000
\end{array}\right.
\end{aligned}
$$

From the ROI rate point of view, the objective was to obtain a positive percentage, at an average rate, up to $5 \%$.

$$
\text { Estimated ROI }=\left\{\begin{array}{c}
1, \text { over } 5 \% \\
0, \text { up to } 5 \%
\end{array}\right.
$$

Since the aim is to achieve the return on investment in the shortest time, we will follow the values obtained up to one year.

$$
\text { ROI time }=\left\{\begin{array}{l}
1, \text { up to } 1 \text { year } \\
0, \text { up to } 5 \text { years }
\end{array}\right.
$$

To obtain the scores of the independent variables: centralization, inter-organizational confidence, inter-organizational market orientation and the advantage offered by a new product, the arithmetic mean of the elements for each variable was calculated.

The dependent variable is found in the database under the name IoT adoption, described with the help of question no. 10 from the questionnaire.

$$
\text { IoT adoption }=\left\{\begin{array}{cc}
1, & \text { if IoT technology were adopted } \\
0, & \text { if IoT technology weren't adopted }
\end{array}(6)\right.
$$

According to Figure 1, we can report that the variables Company size $(B=3,098$, sig $=0.004)$, Financial resources $(\mathrm{B}=5,191$, sig $=0,000)$, New Product Advantage $(\mathrm{B}=1,965$, sig $=0.014)$, Estimated ROI rate $(B=5,409$, sig $=0.002)$ they still have a significant effect $(\operatorname{sig}<0.05)$, 
representing important predictors of the adoption of specific IoT technology, supporting hypotheses $\mathrm{H} 1, \mathrm{H} 2, \mathrm{H} 6, \mathrm{H} 7$.

\begin{tabular}{|c|c|c|c|c|c|c|c|c|c|}
\hline & & B & S.E. & Wald & df & Sig. & $\operatorname{Exp}(B)$ & Lower & Upper \\
\hline \multirow[t]{9}{*}{ Step $1^{a}$} & Company size & 3.098 & 1.088 & 8.102 & 1 & .004 & 22.159 & 2.624 & 187.093 \\
\hline & Financial resources & 5.191 & 1.404 & 13.666 & 1 & .000 & 179.668 & 11.460 & 2816.754 \\
\hline & $\begin{array}{l}\text { Centralızation } \\
\text { Inter-organizational }\end{array}$ & -.694 & .673 & 1.063 & 1 & .303 & .500 & .133 & 1.869 \\
\hline & Trust & -.342 & .508 & .451 & 1 & .502 & .711 & .262 & 1.925 \\
\hline & IO Market Orientation & 1.110 & .608 & 3.328 & 1 & .068 & 3.033 & .921 & 9.992 \\
\hline & New product & 1.965 & .799 & 6.051 & 1 & .014 & 7.138 & 1.491 & 34.170 \\
\hline & $\begin{array}{l}\text { advantage } \\
\text { Estimated ROI rate }\end{array}$ & 5.409 & 1.724 & 9.844 & 1 & .002 & 223.511 & 7.616 & 6559.307 \\
\hline & ROI Time & -.576 & .982 & .344 & 1 & .557 & .562 & .082 & 3.852 \\
\hline & Constant & -12.739 & 4.447 & 8.205 & 1 & .004 & .000 & & \\
\hline
\end{tabular}

a. Variable(s) entered on step 1: Dimensiune, ResurseFinanciare, Centralizare, Incredere, Orientare, AvantajProdus Nou, ROIEstimat, Timp_ROI.

Figure 1 The combined effect of independent variables concerning the dependent variable

Although support was found for two of the assumptions related to the forecasting of organizational factors, regarding the degree of centralization, it seems that it did not prove to be significant $(B=-0.694$, sig $=0.303)$, contributing to the rejection of the $\mathrm{H} 3$ hypothesis. The inter-organizational factors do not have a notable influence for the adoption of IoT, hypotheses $\mathrm{H} 4, \mathrm{H} 5$ are not accepted, due to the fact that there was no significant effect from the point of view of the independent variables Inter-organizational Trust $(B=-, 342$, sig $=0.502)$, Interorganizational market orientation $(B=1,110, \mathrm{sig}=0.068)$, even though the inter-organizational market orientation factor is approaching a statistical significance. The results also do not support the hypothesis $\mathrm{H} 8$, the time for the recovery of the investment is not a significant provider of IoT adoption, the expected period of time before achieving the ROI rate is higher than expected $(\mathrm{B}=-, 576$, sig $=0.557)$, so that organizations with longer time horizons (up to 5 years) are more likely to adopt IoT technology.

\begin{tabular}{|c|c|}
\hline Hypothesis & Result \\
\hline $\mathrm{H} 1$ & Accepted \\
\hline $\mathrm{H} 2$ & Accepted \\
\hline $\mathrm{H} 3$ & Rejected \\
\hline $\mathrm{H} 4$ & Rejected \\
\hline H5 & Rejected \\
\hline H6 & Accepted \\
\hline $\mathrm{H} 7$ & Accepted \\
\hline H8 & Rejected \\
\hline
\end{tabular}

In conclusion, the organizational factors alongside the technological ones have a partial contribution and a significant effect on the adoption of IoT technology, while the interorganizational factors have no effect.

\section{Conclusions}

The purpose of the research was to examine the factors that influence the adoption of IoT technologies in supply chain management. The results of the study show that, in general, the model built on the variables that define the factors that underlie each member company of the supply chain is statistically significant. The organizational factors characterized by the size and financial resources, together with the technological ones, in particular, the advantage offered by a new product and the rate of return on investment are important predictors of the adoption 
www.conferenceie.ase.ro

of IoT technology. The inter-organizational factors inter-organizational confidence and interorganizational orientation on the market together with the organizational factor specific to the degree of centralization and the technological factor specific to the time of reaching the ROI rate do not significantly influence the adoption of the IoT technology in the management of the supply chains.

\section{References}

[1] T. Bush, PESTLE Analysis: Technological Factors Affecting Business. 2016. [Online] Available at: https://pestleanalysis.com/technological-factors-affecting-business/, [Accessed 0202 2020].

[2] R. Calantone, R. Cooper, New Product Scenarios: Prospects for Success. Journal of Marketing, pp. 48-60, 1981.

[3] L. Edelman, M. Suchman, The Legal Environments of Organizations. Annual review of sociology, pp. 479-515, 1997.

[4] A. Guerrieri, V. Loscri, G. Fortino, A. Rosella, A., Management of Cyber Physical Objects in the Future Internet of Things, Springer, 2016.

[5] J. Hage, M. Aiken, Relationship of Centralization to Other Structural Properties. Administrative Science Quarterly, pp. 72-92, 1967.

[6] D.X. Li, H. Wu, L. Shancang, Internet of Things in Industries: A Survey. IEEE Transactions on Industrial Informatics, 10(4), pp. 2233-2243, 2014.

[7] S. Mari, S. Helper, Determinants of Trust in Supplier Relations: Evidence from the Automotive Industry in Japan and the United States. Journal of Economic Behavior and Organization, pp. 387-417, 1998.

[8] M. Noha, A. Walaa, A. Hisham, Impacts of Internet of Things on Supply Chains: A Framework for Warehousing. Social Sciences, 8(10.3390/socsci8030084), p. 84, 2019.

[9] R.D. O'Keefe, J.E. Ettlie, W. P. \& Bridges, Organization Strategy and Structural Differences for Radical versus Incremental Innovation. Management Science, pp. 682-695, 1984.

[10] K.A. Patterson, M.C. Grimm, T. Corsi, Adopting new technologies for supply chain management. Transportation Research Part E: Logistics and Transportation Review, 39(2), pp. 95-121, 2003.

[11] D. Pugh, D. Hickson, C.R. Hinings, C. Turner, The Context of Organization Structures. Administrative Science Quarterly, pp. 91-114, 1969.

[12] H. Standtler, C. Kilger, H. Meyr, Supply Chain Management and Advanced Planning: Concepts, Models, Software, and Case Studies. Springer-Verlag Berlin Heidelberg, 2015.

[13] J.H. Trienekens, P.M. Wognum, A.M., Beulens, J.A. van der Vorst, Transparency in complex dynamic food supply chains. Advanced Engineering Informatics, 26(1), pp. 55$65,2012$.

[14] E. Ulf, Inter-firm Market Orientation: Its Significance and Antecedents in Distribution Networks. Journal of Marketing Management, pp. 633-655, 2012.

[15] G. Varun, An Empirically Derived Model for the Adoption of Customer-Based Interorganizational Systems. Decision Sciences, pp. 603-639, 2003.

[16] V. Venkatesh, S.A. Brown, H. Bala, Bridging the qualitative-quantitative divide: Guidelines for conducting mixed methods research in information systems. MIS quarterly, 37(1), pp. 1317-1323, 2013.

[17] N.C. Wu, M.A. Nystrom, T.R. Lin, H.C. Yu, Challenges to global RFID adoption. Technovation, 26(12), pp. 1317-1323, 2006. 